\title{
The effects of race track surface condition on the racing time of Orlov trotters
}

\author{
Marianna Gladkikh ${ }^{1,}{ }^{*}$ and Olga Kuznetsova ${ }^{1}$ \\ ${ }^{1}$ Russian State Agrarian University, Moscow Timiryazev Agricultural Academy, Timiryazevskaya \\ St., 49, 127550, Moscow, Russia
}

\begin{abstract}
Race speed is one of the main indicators by which trotting horses are estimated. In addition to the horse genotype, race speed is also determined by the influence of environmental factors, such as feeding, keeping, training, and testing conditions. These conditions include of race track surface condition, the rider's qualifications, season of the year, weather conditions. In this paper the influence of race track surface condition on the accuracy of assessing race time is considered. The data of horse trials of Orlov trotters at the Moscow hippodrome were used. The race time of 256 horses at a distance of $1600 \mathrm{~m}$ was assessed. Depending on the weather conditions and the track surface, 9 different track conditions were identified. For the analysis we used data on stallions and mares aged 4 years and older without disaggregation by sex, since there were no significant differences between the average race speed of stallions and mares and it was shown that it was the horses of the older age group that were reliably characterized by the highest average race time with minimal races per horse. It was found that the strength of the influence of the variety of race tracks on the variety of assessments of race time is reliable and amounted to $23.5 \%$. When analyzing the group of the fastest horses, this indicator turned out to be higher and amounts to $43.8 \%$. It is also shown that the selection of horses for breeding work is more expedient and accurate to carry out according to the average race time of the horse for a number of races, and not according to its best result, since in this case the stability of performances is not taken into account.
\end{abstract}

\section{Introduction}

Race is one of the main (if not the most important) trait by which horses of trotting breeds could be evaluated. The assessment of racing time is carried out mainly at the racecourses. Usually Orlov trotters are tested from the age of two and, based on the results of racecourses trials, a conclusion is made about the breeding value of this horse and its further use, including for breeding purposes.

Breeders obtain data on this trait as a result of regular tests over several years at the racecourse. That is why racecourses are an integral part of the horse breeding industry as a kind of laboratory for testing of horse breeding products. According to the Russian

\footnotetext{
*Corresponding author: marianna1001@yandex.ru
} 
«Livestock Breeding Law», the racecourse is an organization for accounting, control, assessment of the level of productivity and product quality. It takes into account the genotypic and phenotypic characteristics of breeding animals to use of these traits in animal breeding.

When evaluating the race time of horses, the accuracy of this assessment is very important, which depends on many factors: both on the quality of the horse itself and on the totality of trial conditions, which can both be favorable for the manifestation of the maximum possible race speed under these conditions, and, conversely, not let the horse show its capabilities.

Therefore, the determination of the strength and reliability of the influence of factors on the accuracy of evaluation of trotting horses by race speed seems to us relevant, both from a theoretical and practical point of view.

We found it is necessary to analyze how the trial conditions, and, first of all, race track surface condition, affect the accuracy of the race time evaluation. A certain number of studies have been carried out on this issue, but mainly the object was Thoroughbred horses or Arabian breeds [1-7].

All scientists agreed that the track distance, track surface condition and even the temperature of track could affect the racing time it takes for a horse to cover a distance. In our investigation we considered only one factor - the quality of the track surface, and its influence on the racing time of the Orlov trotters in the conditions of the Moscow Hippodrome.

\section{Material and methods}

The material for our investigation was programs with the results of horse trials of the Moscow Hippodrome in 1931 from the library of Dmitry A. Kislovsky in the amount of 45 books.

More than 1000 horses of the Orlov trotter breed aged 2 years or more, mares and stallions were selected. The number of effective races per one horse is ranged from 5 to 14 , but there were no horses with less than 5 data. Estimated trait is race time at $1600 \mathrm{~m}$.

Qualifying races were not taken into account, because the horse does not show their high results, but are only proved to have the right to participate in trials with other horses.

In two-round races, each round was treated as a separate round. Race time at a distance of $2400 \mathrm{~m}$ and $3200 \mathrm{~m}$ was recalculated to $1600 \mathrm{~m}$.

All horses came from the same stud farms and were trained from the age of 2 at the Moscow Hippodrome in the same conditions.

Trials' results and weather conditions were official data, which were recorded by the panel of judges.

To process the data, we used the methods of one-way layout variance analysis and rank correlation.

The results were analyzed statistically with Microsoft Excel. The significance of the differences was calculated by the Student's test with the following significance levels: * $\mathrm{P}<0,05 ; * *-\mathrm{P}<0,01 ; * * *-\mathrm{P}<0,001$.

\section{Results and discussion}

Before studying the influence of various factors on the variety of horses in terms of racing time, it was necessary to establish how much different horses of different age and sex can be differentiated in this trait (Table 1).

We divided all horses by sex: into mares and stallions, and each of these groups - into horses aged 3 years, 4 years old and over 4 years old. This division is due to the fact that this system is adopted at the Russian racetracks. 
Table 1. Characteristics of the racing time of stallions and mares depending on their age

\begin{tabular}{|c|c|c|c|c|}
\hline \multirow{2}{*}{ Sex } & \multirow{2}{*}{ Age } & \multicolumn{3}{|c|}{ Race time } \\
\hline & & $\mathrm{M}, \mathrm{c}$ & $\mathrm{m}, \mathrm{c}$ & $\mathrm{Cv}, \%$ \\
\hline \multirow{3}{*}{ Mare } & 3 years old & $143.1 *$ & 1.1 & 2.95 \\
\hline & 4 years old & 134.2 & 0.5 & 0.98 \\
\hline & over 4 years old & 139.1 & - & - \\
\hline \multirow{3}{*}{ Stallions } & 3 years old & $141.3 *$ & 1 & 3.79 \\
\hline & 4 years old & 135.6 & 0.9 & 2.15 \\
\hline & over 4 years old & 130.6 & 0.8 & 1.88 \\
\hline
\end{tabular}

$* P<0,05, * * P<0,01, * * * P<0,01$

A significant superiority of both older mares and stallions over younger mares and stallions was found. There were no significant differences in average race time between mares and stallions of the same age. Therefore, to study the influence of factor, we considered as one group of horses of the same age - 4 years and older, both mares and stallions, a total of 256 heads.

Table 2 shows the different surfaces of the race tracks, which have been identified by the judges before the each trial. The condition of the tracks depends on a number of factors weather conditions, coverage, etc.

Table 2. Classification of race track surface

\begin{tabular}{|l|}
\hline concreted \\
\hline tarmac \\
\hline easy \\
\hline hard \\
\hline broken \\
\hline medium \\
\hline snowy \\
\hline heavy \\
\hline very heavy \\
\hline
\end{tabular}

Certainly, that it is much easier for a horse to run on a track surface that is qualified as «easy» than on a «very heavy» track surface.

Next, we evaluated the strength of the influence of the variety of track surfaces on the variety of assessments of the race time.

The analysis results are presented in Table 3.

Table 3. Results of one-way analysis of variance $(n=2094$ races).

\begin{tabular}{|l|r|l|r|r|r|}
\hline \multicolumn{1}{|c|}{ Track surface } & n, races & M, c & $\sigma, c$ & $\begin{array}{c}\mathrm{C}_{\mathrm{v}}, \\
\%\end{array}$ & $\mathrm{~m}, \mathrm{c}$ \\
\hline concreted (a) & 126 & 148.3 & 6.188 & 4.2 & 0.55 \\
\hline tarmac (b) & 80 & 149.1 & 8.708 & 5.8 & 0.97 \\
\hline hard (c) & 228 & $151.4^{* \mathrm{ab}}$ & 6.460 & 4.3 & 0.43 \\
\hline easy (d) & 868 & $151.5^{* \mathrm{ab}}$ & 7.752 & 5.1 & 0.26 \\
\hline very heavy (e) & 186 & $163.5^{* *}$ & 7.011 & 4.3 & 0.51 \\
\hline broken (f) & 32 & $151 *^{* \mathrm{ab}}$ & 5.546 & 3.7 & 0.98 \\
\hline snowy (g) & 99 & $154.1^{* \mathrm{k} \text { abcdf }}$ & 6.910 & 4.5 & 0.69 \\
\hline medium (i) & 145 & $153.7^{* \mathrm{k} \text { abcdf }}$ & 8.208 & 5.3 & 0.68 \\
\hline
\end{tabular}




\begin{tabular}{|l|r|r|r|r|r|}
\hline very heavy $(\mathrm{k})$ & 330 & $158.6 *$ abcdf & 7.986 & 5.0 & 0.44 \\
\hline$* P<0,05, * * P<0,01, * * * P<0,01$ \\
\hline
\end{tabular}

\begin{tabular}{|c|c|c|c|}
\hline \multirow{2}{*}{ Indicator } & \multicolumn{3}{|c|}{ Variance } \\
\cline { 2 - 4 } & $\mathrm{x}$ & $\mathrm{z}$ & $\mathrm{y}$ \\
\hline $\mathrm{C}_{\mathrm{i}}$ & 37030.8 & 120340 & 157370 \\
\hline $\mathrm{y}_{\mathrm{i}}{ }^{2}=\mathrm{C}_{\mathrm{i}} / \mathrm{C}_{\mathrm{y}}$ & 0.235 & 0.765 & 2093 \\
\hline $\mathrm{v}_{\mathrm{i}}$ & 8 & 2085 & 75.19 \\
\hline$\sigma_{\mathrm{i}}{ }^{2}=\mathrm{C}_{\mathrm{i}} / \mathrm{v}_{\mathrm{i}}$ & 4628.85 & 57.72 & \\
\hline
\end{tabular}

$\mathrm{F}_{\text {fact. }}=80.2$

$\mathrm{F}_{\text {st. }}=1.9: 2.5: 3.4$

$$
\mathrm{v}_{1}=8
$$

It was found that the strength of the influence of different types of tracks surface on the variety of race time assessments is reliable and amounted to $23.5 \%$.

In addition, the variety of results (coefficient of variation, $\mathrm{C}_{\mathrm{v}}$ ) shown by trotters on different surface types is approximately the same. It could mean that different horses equally reduced or increased the time to cover the distance, depending on the quality of the track surface.

All race tracks were reliably divided into four clusters: the first, with the easiest surface, included «concrete» and «tarmac» tracks, the second - «hard», «easy», «broken», the third «snowy», «medium», «heavy», and the fourth cluster had only one type of track surface «very heavy», on which all horses performed significantly low race speed and, therefore, highest race time.

We hypothesized that, perhaps, the influence of the race track surfaces was superimposed on the fact that horses of different race classes could run mainly or only on the tracks of the same surfaces.

To ensure that horses of different classes were randomly assigned to different track surface types, we compiled a distribution of horses for different track surfaces, an element of which is presented in Table 4.

Table 4. Distribution of horses of one and the same race class for different race track surfaces, $\%$

\begin{tabular}{|l|c|c|c|c|c|c|c|c|}
\hline \multirow{2}{*}{ Horse name } & \multicolumn{7}{|c|}{ Track surfaces } \\
\cline { 2 - 10 } & concreted & tarmac & easy & hard & medium & snowy & heavy & $\begin{array}{c}\text { very } \\
\text { heavy }\end{array}$ \\
\hline Agava & & & 37.5 & & 25 & & 25 & 12.5 \\
\hline I & & 12.5 & 62.5 & 12.5 & & & 12.5 & \\
\hline Aliment & 14.3 & & 42.8 & & & 14.3 & 28.6 & \\
\hline Ametist & 12.5 & 12.5 & 25 & 25 & & & 12.5 & 12.5 \\
\hline Burlak & & & 57.1 & & 28.6 & & 14.3 & \\
\hline Vlastnaya & & & 33.3 & & & 33.3 & 33.3 & \\
\hline Naslednitsa & 11.1 & & 44.4 & & 11.1 & & 22.2 & 11.1 \\
\hline Patriot & 18.2 & 9.1 & 27.3 & 9.1 & 18.2 & & 18.2 & \\
\hline Provincialka & 16.7 & & 50 & & 16.7 & & 16.7 & \\
\hline Scoba & 20 & 40 & 20 & 20 & & & & \\
\hline
\end{tabular}


From the table, it can be seen that the distribution of races on different types of track surfaces may differ from horse to horse: mostly horse were performed on tracks with easy surface and heavy surface, of the - on the tracks with concreted and medium surfaces and very seldom - on the tracks with snowy, tarmac, hard and very heavy surfaces.

Therefore, we decided to try to smooth out the influence of the race time class and, that's why, formed a group of 10 horses that showed the highest race time results.

Table 5 shows the results of the analysis of influence of the track surfaces on the accuracy of the assessment of race time in the group of the fastest horses.

Table 5. Results of one-way analysis of variance $(n=82$ races $)$ in group of fastest trotters.

\begin{tabular}{|c|c|c|c|c|c|}
\hline Track surface & $\mathrm{n}$, races & $\mathrm{M}, \mathrm{c}$ & $\sigma, \mathrm{c}$ & $\mathrm{C}_{\mathrm{v}}, \%$ & $\mathrm{~m}, \mathrm{c}$ \\
\hline concreted (a) & 7 & 139.2 & 2.481 & 1.8 & 0.94 \\
\hline tarmac (b) & 5 & 138.9 & 2.328 & 1.7 & 1.04 \\
\hline hard (c) & 5 & 143.5 & 4.120 & 2.9 & 1.84 \\
\hline easy (d) & 30 & 140.2 & 4.019 & 2.9 & 0.73 \\
\hline very heavy (e) & 3 & $150.9^{*}$ & 2.988 & 2.0 & 1.73 \\
\hline broken (f) & 2 & 140.6 & 5.307 & 3.8 & 3.75 \\
\hline snowy (g) & 9 & $144.7^{*}$ & 4.513 & 3.1 & 1.50 \\
\hline medium (i) & 14 & $147.9^{*}$ & 4.362 & 2.9 & 1.17 \\
\hline very heavy (k) & 7 & 139.2 & 2.481 & 1.8 & 0.94 \\
\hline
\end{tabular}

\begin{tabular}{|c|c|c|c|}
\hline \multirow{2}{*}{ Indicator } & \multicolumn{3}{|c|}{ Variance } \\
\cline { 2 - 4 } & $\mathrm{x}$ & & $\mathrm{x}$ \\
\hline $\mathrm{C}_{\mathrm{i}}$ & 970,4 & 1247,4 & 2217,8 \\
\hline $\mathrm{y}_{\mathrm{i}}{ }^{2}=\mathrm{C}_{\mathrm{i}} / \mathrm{C}_{\mathrm{y}}$ & 0,438 & $0,56,2$ & 1 \\
\hline$v_{\mathrm{i}}$ & 7 & 67 & 74 \\
\hline$\sigma_{\mathrm{i}}{ }^{2}=\mathrm{C}_{\mathrm{i}} / v_{\mathrm{i}}$ & 138,63 & 18,62 & 29,97 \\
\hline
\end{tabular}

$\begin{array}{lr}\mathrm{F}_{\text {fact. }}=7,44 & \mathrm{v}_{1}=7 \\ \mathrm{~F}_{\text {st. }}=2,1: 2,9: 4,1 & \mathrm{v}_{2}=68\end{array}$

The table shows that the influence of the factor (the variety of track surfaces) is reliable and amounts to $43.8 \%$. Moreover, in this group of sharpest horses, the dependence of trial results on the condition of the track surface is almost two times higher than in the whole sample.

Further, it seemed interesting to determine how the rank of a horse race time changes if we select not according to the single best result, but according to the average mean for a number of races.

The data are presented in Table 6.

Table 6. Ranking the top 10 horses with highest race time.

\begin{tabular}{|l|c|c|}
\hline \multicolumn{1}{|c|}{ Name of horse } & $\begin{array}{c}\text { Rank } \\
\text { by the best result }\end{array}$ & $\begin{array}{c}\text { Rank } \\
\text { by the average result }\end{array}$ \\
\hline Provincialka & 1 & 2 \\
\hline Ametist & 2 & 3 \\
\hline
\end{tabular}




\begin{tabular}{|l|c|c|}
\hline Vlastnaya & 3 & 4 \\
\hline Aliment & 4 & 9 \\
\hline Agava & 5 & 8 \\
\hline Burlak & 6 & 7 \\
\hline Patriot & 7 & 6 \\
\hline Naslednitsa & 8 & 10 \\
\hline I & 9 & 5 \\
\hline Scoba & 10 & 1 \\
\hline
\end{tabular}

It was found that the rank of the horse for the best single result does not coincide with the rank for the average indicator of agility.

The calculated rank correlation coefficient was 0.16 . There is a strong mixing of ranks, when evaluating a horse by the best shown result and by the average result over a number of races.

It means that when breeders select the horses based on their best race time, horses showing stable results are selected with a probability of $16 \%$.

In practice breeders, on the other hand, are mainly guided by the best result that the horse has shown, without considering the favorable and unfavorable environmental factors.

We can assume that a horse shows its best race time when most of the factors affecting the variety of time to cover race distance, including the type of track surface, are relatively ideal, and when calculating the average result, those that the horse showed even with a less successful combination of factors are taken into account.

\section{Conclusion}

Thus, the quality of the track surface on which horses are tested affects the accuracy of assessing their breeding value based on race time, the power of influence is $23.5 \%$.

This means that almost a quarter of the difference between the race time of even the same horse shown in a number of races may depend on what type of surface it was running on.

That is why it is necessary to carry out measures so that the influence of the quality of the track surface on the test results becomes minimal due to the use of modern materials for surface, careful maintenance of tracks, and testing on one special - prize - track.

This is especially actual for the group of the sharpest horses, in which the influence of the variety of track surfaces on the variety of the results of evaluating horses is almost twice higher as for all evaluated horses as a whole $-43.8 \%$.

Also, to compare the results of Orlov trotters for breeding use, it should be borne in mind that there is a strong mixing of ranks (rank correlation coefficient 0.16 ) between data when we take in consideration the best race time of the horse and data, when we take the average indicator of race time for a number of races.

\section{References}

1. Y. Maeda, M. Tomioka, M. Hanada, M. Oikawa, Journal of Equine Veterinary Science, 32(11), 689-695 (2012)

2. Y. Moritsu, H. Funakoshi, I. Shun, J.Equine.Sci. 5(2), 53-58 (1994)

3. A. Köseman, C. Özbeyaz, Ankara Üniv Vet Fak Derg, 56, 219-224 (2009)

4. H. Oki, Y. Sasaki, R. L. Willham, Journal of Animal Breeding and Genetics, 111, 128137 (1994) https://doi.org/10.1111/j.1439-0388.1994.tb00446.x.

5. H. Orhan, A. Kaygisiz, Asian Journal of Animal and Veterinary Advances, 5, 112-119 (2010) 
6. M. L. Peterson, R. F. Reiser II, P.-H. Kuo, D. W. Radford, C. W. Mc ilwraith, Equine Veterinary Journal, 42, 351-357 (2010) https://doi.org/10.1111/j.20423306.2010.00072.x.

7. Federal Law № 123 - «Breeding Law», 03.081995 Collection of Legislation of the Russian Federation 32 (1995)

8. J. Northrop, J. H. Martin, D. Holt, S. J. Hobbs, Operational temperatures of all-weather thoroughbred racetracks influence surface functional properties, Biosystems Engineering, 193, (37-45) (2020) 10.1016/j.biosystemseng.2020.02.003

9. R. Behnke, Numerical time-domain modelling of hoof-ground interaction during the stance phase, Equine Veterinary Journal, 50, 4(519-524) (2017) 10.1111/evj.12782 